\title{
EFEKTIFITAS MEDIA BECAK DALAM PEMBELAJARAN IPA UNTUK MENINGKATKAN KETRAMPILAN BERFIKIR KRITIS SISWA SD/MI
}

\author{
Galuh Tisna Widiana, Maufuzul Ulum, \\ Triya Nurrohmah \& Achmad Zainul Hasan Arobi \\ galuh_widiana@yahoo.com \\ Pendidikan Guru Marasah Ibtidaiyah \\ Fakultas Agama Islam \\ Universitas Pesantren Tinggi Darul Ulum Jombang
}

\begin{abstract}
Abstrak: "Becak" is one of three dimensional visual media that can be concrete the student's understanding towards the material of transplantation. Because of becak media, student's can see participate. Student's will be easy to understand the material because it's practical and should be visualized. The aim of this media is student's can practice "Becak" (Belajar Cangkok) media in the IPA learning. It's to develop the critical thinking skills of student's elementary school. This research uses experiental method and research variabel uses pre-test and post-test. By using this method, the researcher will know the understanding from each student. How the apply the media correctly. By the concrete media and the participation of students's the learning process will be impressive. So that the student's understanding will grow on their own in the way they participate in the learning process.
\end{abstract}

Keywords: effectiveness, media, critical.

\begin{abstract}
Abstrak: Media "Becak" adalah suatu media visual tiga dimensi yang dapat mengkonkritkan pemahaman siswa terhadap materi pencangkokan. Karena dalam media becak siswa dapat melihat dan terlibat langsung dengan medianya, dan siswa lebih mudah untuk memahami materi mencangkok karena materi yang praktis dan harus divisualisasikan serta butuh praktek dalam pembelajarannya. Tujuan digunakan media seperti ini agar siswa mampu menerapan media becak (belajar cangkok) dalam pembelajaran IPA guna meningkatkan ketrampilan berfikir kritis siswa SD/MI, metode yang digunakan yaitu eksperimental, variabel penelitian serta menggunakan pre test dan post test. Metode di atas digunakan untuk mengetahui pemahaman dari masing-masing siswa bagaimana cara mereka mengaplikasikan media tersebut dengan benar. Jadi dengan menggunakan media yang konkrit dan siswa terlibat langsung maka pembelajaran mereka menjadi berkesan serta pemahamanya akan terpupuk sendiri dengan cara mereka ikut serta dalam proses pembelajaranya.
\end{abstract}

Kata kunci: efektifitas, media, berfikir kritis.

\section{PENDAHULUAN}

Pembelajaran ilmu pengetahuan alam (IPA) di SD merupakan suatu pembelajaran yang dapat menambah pengetahuan siswa di alam sekitarnya, yang diperoleh dari pengalaman melalui serangkaian proses ilmiah antara lain penyelidikan, penyusunan dan pengujian gagasan-gagasan. Hal itu sesuai dalam kurikulum Badan standar nasional pendidikan (BSNP 2007:139) mengemukakan bahwa: "IPA berhubungan dengan cara mencari tahu tentang alam secara sistimatis sehingga IPA bukan hanya penguasaan 
Galuh, Maufuzul, Triya, dan Achmad, Efektifitas Media Becak dalam...

kumpulan pengetahuan yang berupa fakta-fakta, konsep-konsep atau prinsip-prinsip saja tetapi juga merupakan suatu proses penemuan.

Di sekolah dasar pendidikan IPA juga merupakan salah satu program pembelajaran yang bertujuan untuk menanamkan dan mengembangkan pengetahuan, keterampilan sikap, dan nilai ilmiah kepada siswa serta rasa mencintai dan menghargai kebesaran Tuhan Yang Maha Esa. Sehubungan dengan itu Abruscato, (Khaerudin dan Soedjono 2005:15 dalam Rini) mengemukakan bahwa "tujuan pembelajaran IPA diajarkan di kelas adalah (1) mengembangkan kognitif siswa, (2) mengembangkan afektif siswa, (3) mengembangkan psikomotorik siswa, (4) mengembangkan kreatifitas siswa, serta (5) melatih siswa berpikir kritis".

Ketrampilan berfikir kritis dalam pembelajaran IPA sangat di perlukan karena konsep dalam pembelajaran IPA merupakan konsep lingkungan alam sekitar yang memerlukan medianya langsung bukan dengan melihat gambar semata. Menurut Ennis (1996), keterampilan berpikir kritis merupakan bagian dari pola berpikir tingkat tinggi yang terjadi dalam sistem kognitif siswa untuk membandingkan antara pengetahuan yang dimilikinya dengan permasalahan yang dihadapinya. Keterampilan berpikir kritis menggunakan dasar proses berpikir untuk menganalisis argumentasi dan memunculkan gagasan terhadap setiap interpretasi sehingga siswa dapat mengembangkan pola penalaran yang logis

Dari pemaparan bahasan di atas, tampak jelas bahwa guru harus membuat pembelajaran itu lebih efisien dan inovatif sehingga dapat memunculkan sifat kritis dan rasa ingintahu siswa terhadap pembelajaran IPA SD/MI. Agar tujuan pembelajaran yang diharapkan dapat tercapai dengan maksimal. Dengan menerapkan berbagai metode, strategi, dan media yang tepat terutama media yang dapat memvisualisasi sesuatu ilmu pengetahuan.

Dalam pembelajaran di sekolah, terdapat banyak unsur saling berkaitan dan menentukan keberhasilan dalam proses belajar-mengajar. Unsur-unsur tersebut adalah: pendidik (guru), (peserta didik (siswa, kurikulum, pengajaran, tes, dan lingkungan dalam kegiatan belajar-mengajar (Sudjana 2001: 2).

Salah satu tugas guru adalah menciptakan suasana pembelajaran dapat memotivasi siswa untuk senantiasa belajar dengan baik dan semangat. Suasana pembelajaran yang demikian akan berdampak positif dalam pencapain prestasi belajar yang optimal. Oleh karena itu, guru sebaiknya memilih media pembelajaran yang tepat. Ketidak tepatan dalam penggunaan media akan menimbulkan kejenuhan bagi siswa dalam menerima materi yang disampaikan sehingga materi kurang dapat dipahami yang akan mengakitbatkan siswa menjadi apatis.

Perkembangan kognitif anak usia Sekolah Dasar pada hakikatnya berada dalam operasi kongkret. Siswa sudah dapat memahami konsep-konsep yang sangat sederhana, dan masih dipengaruhi oleh obyek-obyek visual. Dalam rangka meningkatkan kualitas pembelajaran dan prestasi belajar di SD/ MI perlu adanya upaya menumbuhkembangkan kecintaan siswa terhadap matapelajaran melalui inovasi dalam pelaksanaan pembelajaran agar lebih menarik dan menyenangkan. Hal ini dapat dilakukan dengan 
Galuh, Maufuzul, Triya, dan Achmad, Efektifitas Media Becak dalam...

metode pengajaran yang bervariasi dan mengoptimalkan penggunaan media pembelajaran.

Media "Becak" adalah suatu media visual tiga dimensi yang dapat mengkonkretkan pemahaman siswa terhadap materi pencangkokan. Media belajar mencangkok "Becak" diharapkan dapat memvisualisasi pembelajaran mencangkok sehingga dirancang dalam bentuk tiga dimensi sehingga dapat memahami materi. Karena dalam media becak siswa dapat melihat dan terlibat langsung dengan medianya. Dan siswa dapat lebih mudah untuk memahami materi mencangkok yang merupakan materi praktis yang harus divisualisasikan serta butuh praktek dalam pembelajarannya. Dengan hal itu media Becak dapat mengaktifkan guru serta siswa sesuai dengan penelitian dari Ari Krisnawati dan Suppriyono yang menyatakan bahwa: Hasil Penelitian menunjukkan bahwa prosentase aktivitas guru mengalami peningkatan sebesar $13,5 \%$ dari $74 \%$ pada siklus I menjadi $87,5 \%$ pada siklus II. Aktivitas siswa mengalami peningkatan sebesar $20 \%$ dari $74 \%$ pada siklus I menjadi $94 \%$ pada siklus II. Hasil belajar siswa juga mengalami peningkatan pada siklus I $63 \%$ dan siklus II menjadi $89 \%$. Dari hasil tersebut dapat disimpulkan bahwa penggunaan media tiga dimensi dapat meningkatkan aktivitas guru, aktivitas siswa dan hasil belajar siswa kelas IIIC di SDN Manukan Kulon Tandes Surabaya.

\section{METODE}

Dalam penelitian ini digunakan metode observasi dengan menggunakan sumber data primer, sumber data yang dikumpulkan oleh peneliti. Dalam penelitian ini sumber data primernya adalah siswa MIN Rejoso kelas V Jombang.

Data dalam penelitian ini dapat diperoleh dari:

a. Person, yaitu sumber data yang dapat memberikan data berupa jawaban tertulis, sumber data berupa jawaban tertulis melalui pre test dan post test.

b. place, yaitu sumber data yang menyajikan keadaan obyek untuk penggunaan metode observasi.

\section{Rancangan Penelitian}

Penelitian menggunakan rancangan "one group pretest-posttest design", di mana digunakan satu kelompok subyek. Pertama-tama dilakukan uji awal, lalu dikenakan perlakuan untuk jangka waktu tertentu. Kemudian dilakukan uji akhir. Rancangan penelitian dapat digambarkan sebagai berikut (Tuckman, 1978:129):

Tabel 3.1 Rancangan Penelitian

\begin{tabular}{|c|c|c|}
\hline \hline Pre test & Perlakuan & Post test \\
\hline $\mathrm{O}_{1}$ & $\mathrm{X}$ & $\mathrm{O}_{2}$ \\
\hline
\end{tabular}


Galuh, Maufuzul, Triya, dan Achmad, Efektifitas Media Becak dalam...

Keterangan gambar:

$\mathrm{O}_{1}=$ uji awal (pretest), untuk mengetahui penguasaan awal siswa terhadap pengetahuan tentang materi sebelum diberikan perlakuan.

$\mathrm{X}=$ Perlakuan, yaitu pelaksanaan pembelajaran denan menggunakan media "Becak" yang dikembangkan untuk jangka waktu tertentu.

$\mathrm{O}_{2}=$ uji akhir (posttest), untuk mengetahui penguasaan siswa terhadap pengetahuan tentang materi

\section{Teknik Pengumpulan Data}

Yang dimaksud dengan teknik pengumpulan data adalah cara yang dilakukan oleh seorang peneliti untuk mengumpulkan data yang diperlukan dalam penelitian. Data penelitian diperoleh dari hasil tes siswa langsung dari sampel penelitian yaitu nilai pre test dan post test.

\section{Teknik Analisis Data}

Tujuan analisis data dalam penelitian ini adalah untuk menjawab pertanyaanpertanyaan penelitian yang selanjutnya merumuskan simpulan. Berikut ini data-data penelitian yang akan dianalisis:

\section{Analisis Data Hasil Pengamatan Aktivitas Siswa}

Data hasil pengamatan aktivitas siswa diperoleh dengan menggunakan lembar pengamatan aktivitas siswa. Data hasil pengamatan yang diberikan oleh dua orang pengamat tentang aktivitas siswa dianalisis secara statistik deskriptif dengan prosentase. Pengamatan aktivitas siswa dalam kegiatan belajar mengajar dilakukan dalam setiap kali pertemuan untuk kelompok tertentu, dan pengamatan dilakukan dalam setiap 5 menit sekali. Waktu pertemuan untuk tiap-tiap 1 jam pelajaran adalah 40 menit, untuk setiap RPP dilakukan 2 jam pelajaran jadi 2 x 40 menit $=80$ menit, sehingga jumlah keseluruhan pengamatan adalah 8 kali.

Berdasarkan rata-rata penilaian dari dua pengamat untuk tiap kategori yang diamati, untuk tiap RPP akan ditentukan prosentasenya dengan rumus:

$$
\mathrm{P}=\left[\frac{\text { Rata-rata dari dua pengamat }}{\sum \text { keseluruhan dari hasil pengamatan yang ditetapkan }}\right] x 100 \%
$$

\section{Persentase Reliabilitas Instrumen Pengamatan Pengelolaan Pembelajaran.}

Reliabilitas instrumen pengelolaan pembelajaran dihitung berdasarkan data statistik deskriptif yang telah ditabulasi.

\section{Analisis Data Respon Siswa}

Data angket diperoleh dari data yang diberikan kepada siswa, yaitu: angket respon siswa terhadap proses pembelajaran. Teknik yang digunakan untuk menganalisis respon siswa adalah statistik deskriptif.

Data angket diperoleh dari angket respon siswa, dianalisis menggunakan perhitungan model ARCS sebagai berikut:

Menggolongkan pernyataan-pernyataan dalam angket respon siswa terhadap pembelajaran berdasarkan kriteria positif atau negatif dan kondisi ARCS, yaitu kondisi 
Galuh, Maufuzul, Triya, dan Achmad, Efektifitas Media Becak dalam...

Attention (perhatian), Relevance (relevansi), Confidence (keyakinan), dan Satisfaction (kepuasan). Seperti dalam Tabel 3.2. berikut:

Tabel 3.2 Penggolongan Pernyataan dalam Angket respon siswa berdasarkan Kriteria dan Kondisi.

\begin{tabular}{|c|c|c|c|}
\hline \multirow{2}{*}{ NO } & \multirow{2}{*}{ Kondisi } & \multicolumn{2}{|c|}{ Angket respon } \\
\cline { 3 - 4 } & & $\begin{array}{c}\text { Nomor Pernyataan } \\
\text { Positif }\end{array}$ & $\begin{array}{c}\text { Nomor Pernyataan } \\
\text { Negatif }\end{array}$ \\
\hline 1 & Perhatian (Attention) & $1,13,19,23$, & $4,9,20$, \\
\hline 2 & Relevansi (Relevance) & $2,5,16,17,18,22$, & 7 \\
\hline 3 & Keyakinan (confidence) & $3,10,21$, & 8 \\
\hline 4 & Kepuasan (Satisfaction) & $6,11,12,14,15,25,26$, & 24 \\
\hline
\end{tabular}

Membuat rekap skor yang diberikan siswa terhadap pernyataan-pernyataan dalam angket respon siswa terhadap pembelajaran dengan ketentuan sebagai berikut:

Untuk pernyataan dengan kriteria positif: $1=$ sangat tidak setuju; $2=$ tidak setuju; $3=$ ragu-ragu; 4 = setuju; dan $5=$ sangat setuju.

Untuk pernyataan dengan kriteria negatif : $1=$ sangat setuju; $2=$ setuju; $3=$ raguragu; 4 = tidak setuju; dan 5 = sangat tidak setuju.

Menghitung skor rata-rata gabungan dari kriteria positif dan negatif tiap kondisi, kemudian menentukan kategorinya dengan ketentuan skor rata-rata 1,00 -1,49 = tidak baik ; 1,50 - 2, 49= kurang baik ; 2,50 - 3,49= cukup baik ; dan 3,50-4,00= sangat baik. ( Hadi, 2009).

\section{HASIL DAN PEMBAHASAN}

Penelitian Efektifitas Media Becak Dalam Pembelajaran IPA Untuk Meningkatkan Ketrampilan Berfikir Kritis Siswa SD/MI yang telah dicapai ada beberapa tahapan yang dilakukan dalam penelitian. Tahap pertama ini yang dilakukan adalah melakukan izin penelitian kepada sekolah yang menjadi objek penelitian ini yaitu MIN Rejoso Peterongan Jombang. RPP digunakan sebagai acuan dalam melakukan pembelajaran, agar pembelajaran dapat terlaksana dengan terstuktur.

Tahap Kedua adalah melakukan pembuatan media becak yang menggunakan benda-benda konkrit, seperti batang pohon mangga, pot,tanah, sabut kelapa. Batang pohon mangga dikupas kemudian dikerik dan diberi tanah yang dibaluti dengan sabut kelapa dan diikat dengan tali, lalu siram dengan air agar tanah tetap lembab dan cepat tumbuh akar. Pohon yang bisa di cangkok yaitu yang memiliki cabang, batang berkayu dan berkeping dua (dikotil). Kemudian merangkai sesuai tahap mencangkok yang sudah dirancang setelah itu membuat rekaman suara yang kemudian dirangkai pada media.

Tahap ketiga adalah melakukan pengambilan data melalui pelaksanaan pembelajaran dengan menggunakan media becak yang dilaksanakan di kelas 5.1 MIN Rejoso Peterongan Jombang yang berjumlah 30 siswa. Tahap terakhir dari penelitian diharapkan siswa dapat merespon media becak dengan baik dan bisa membuat siswa berfikir kritis.

Tahap keempat adalah menganalisis data penelitian dengan hasil pada angket 
Galuh, Maufuzul, Triya, dan Achmad, Efektifitas Media Becak dalam...

respon siswa menjawab dari 38 siswa yang menjawab sangat tidak setuju ada $0 \%$ siswa yang menjawab tidak setuju sebanyak 2,6 \% siswa, siswa yang menjawab raguragu sebanyak 7,8 \% siswa, siswa yang menjawab setuju sebanyak 52,6 \% siswa, dan siswa yang menjawab sangat setuju sebanyak 36,8\% siswa. Dapat disimpulkan respon siswa pada kategori setuju adalah hasil tertinggi. Untuk hasil respon siswa dapat dilihat melalui diagram di bawah ini.

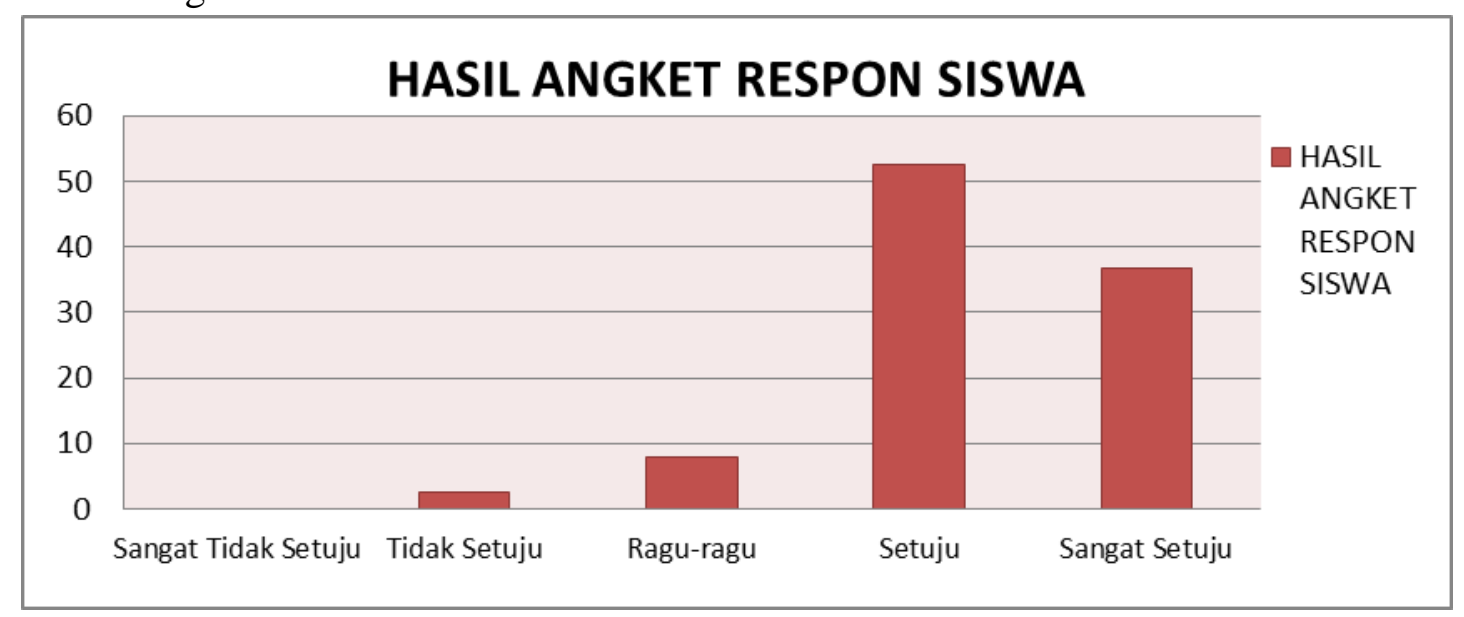

Grafik 1. Hasil Angket Siswa

Pengamatan keterlaksanaan RPP dengan menggunakan media "Becak" dengan hasil pengamatan mendapatkan nilai 4 sebanyak 6, nilai 3 sebanyak 7, nilai 2 sebanyak 3 , nilai 1sebanyak 0 dengan total nilai yaitu 61 maka dapat diakatakan hasil pengamatan keterlaksanaan RPP menggunakan media "Becak" dapat disimpulkan mendapatkan kategori baik. Hasil pengamatan RPP dapat dilihat melalui diagram di bawah ini.

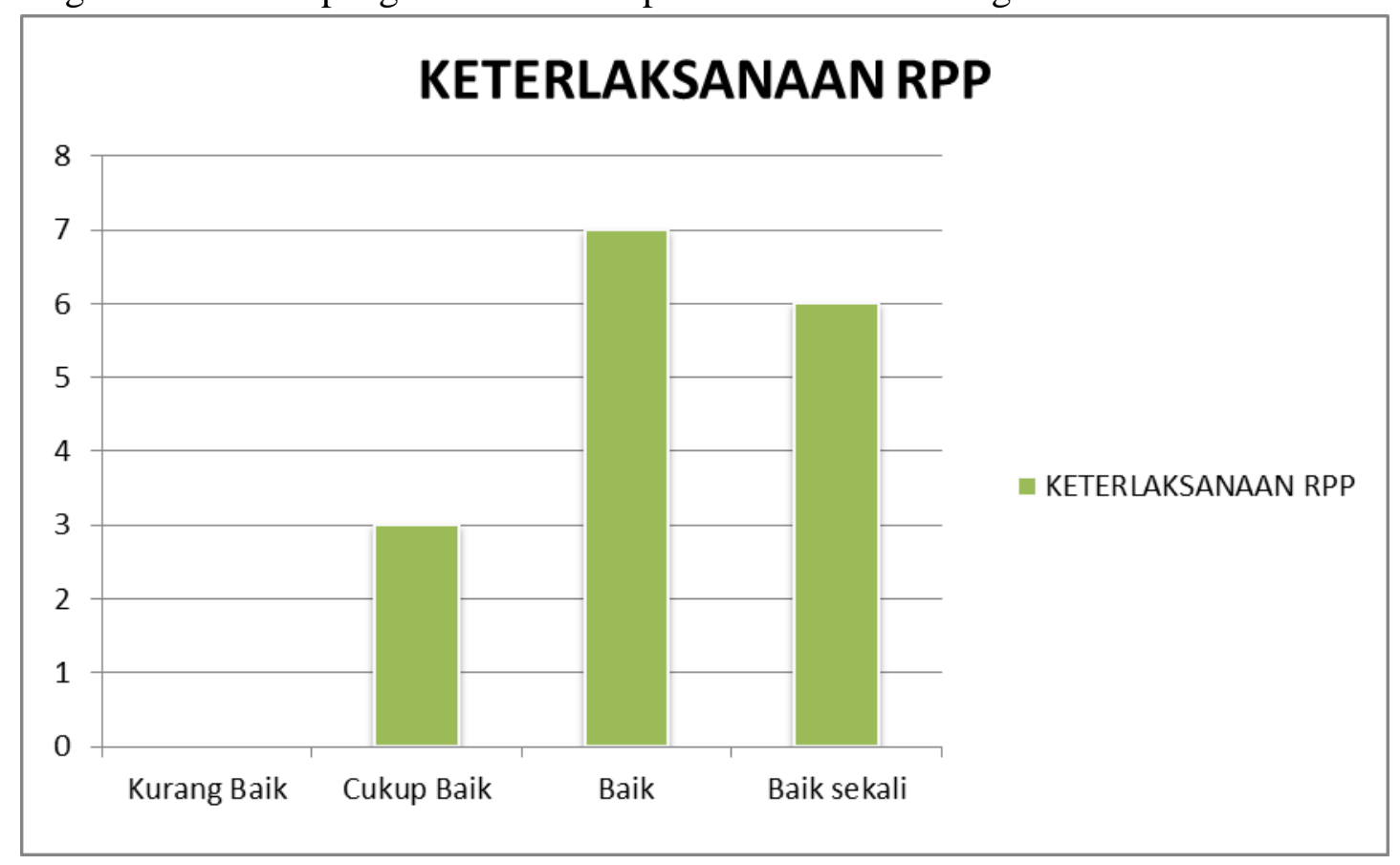

Grafik 2. Hasil Keterlaksanaan RPP 
Galuh, Maufuzul, Triya, dan Achmad, Efektifitas Media Becak dalam...

Pengamatan aktivitas siswa selama kegiatan belajar mengajar dengan hasil pengamatan mendapatkan nilai 4 sebanyak 5, nilai 3 sebanyak 3, nilai 2 sebanyak 0 dan nilai 1 sebanyak 0 dengan total nilai yaitu 29 maka dapat dikatakan hasil pengamatan aktifitas siswa selama kegiatan belajar mengajar kategori baik. Hasil pengamatan aktivitas siswa dapat dilihat pada diagram di bawah ini.

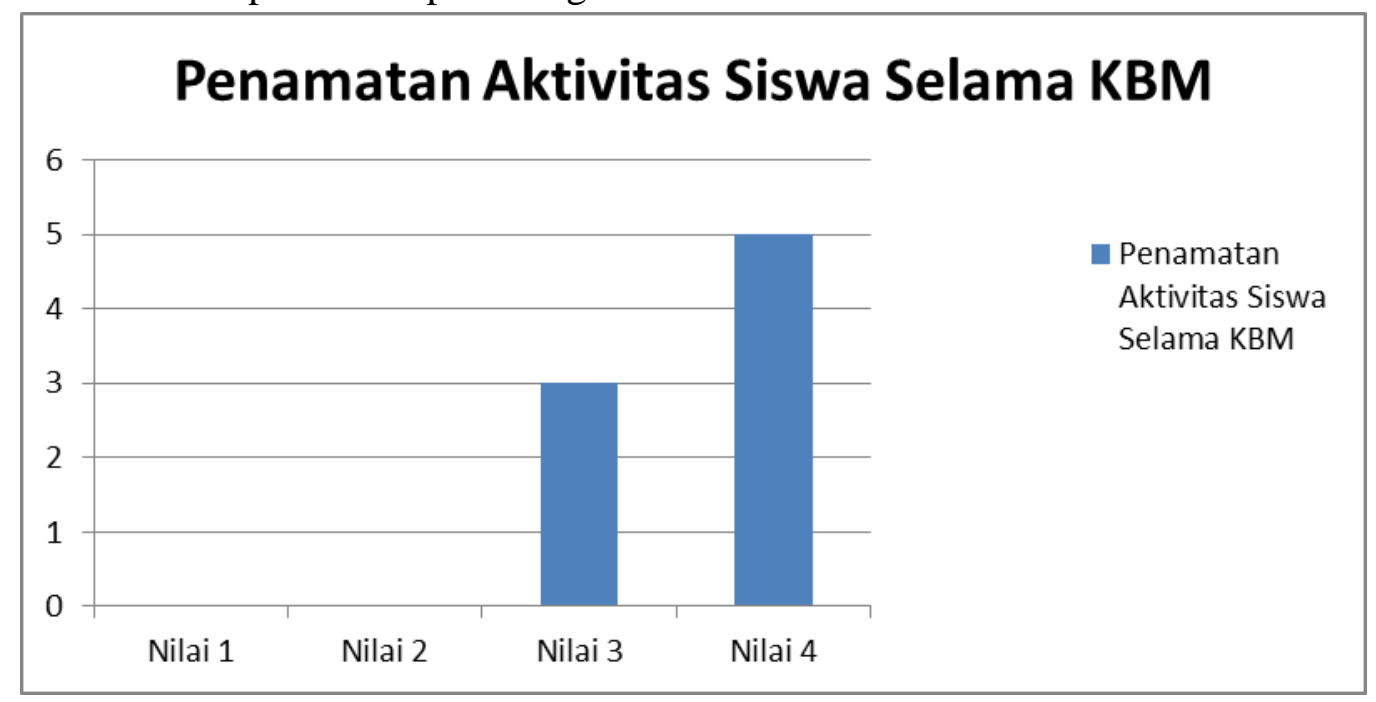

Grafik 3. Hasil Pengamatan Aktivitas Siswa

\section{KESIMPULAN}

Media yang menarik dan konkrit membuat daya respon siswa lebih meningkat dimana mereka terlibat dalam pembelajaanya. Salah satu tugas guru adalah menciptakan suasana pembelajaran yang dapat memotivasi siswa untuk senantiasa belajar dengan baik dan semangat. Suasana pembelajaran yang demikian akan berdampak positif dalam pencapain prestasi belajar yang optimal. Oleh karena itu, guru sebaiknya memilih media pembelajaran yang tepat. Ketidak tepatan dalam penggunaan media akan menimbulkan kejenuhan bagi siswa dalam menerima materi yang disampaikan sehingga materi kurang dapat dipahami yang akan mengakitbatkan siswa menjadi apatis.

\section{DAFTAR RUJUKAN}

Abdullah. 1998. Pendidikan Sains Yang Humanistis. Surabaya: Kanisius.

Ennis Hugh Robert. 1996. Critical Thinking

Rini, dkk. Meningkatkan Hasil Belajar Siswa Melalui Penggunaan Metode Demonstrasi Pada Mata Pelajaran IPA Di Kelas III SDN Inpres Tunggaling. Jurnal Kreatif Tadulako Online Vol. 2 No. 1

Sudjana, D. 2001. Metode dan Teknik Pembelajaran Partisipatif. Bandung : Falah Production.

Sulistyorini, Sri. 2007. Pendidikan Ilmu Pengetahuan Alam UMS.

Suyitno, Amin. 2006. Pemilihan Model-model Pembelajaran dan di Sekolah. Semarang : Universitas Negeri Semarang. 